\title{
Interfacial phenomena in films of monoliquids and binary mixtures in vacuum
}

\author{
Yuri Vyazov, Victor Prihodko, Igor Yarygin and Vyacheslav Yarygin ${ }^{\mathrm{a}}$ \\ Kutateladze Institute of Thermophysics SB RAS, Rarefied Gases Laboratory, 630090, Lavrentieva ave. 1, \\ Novosibirsk, Russia
}

\begin{abstract}
The problem of joint gas outflow with near-wall liquid film from an axisymmetric cylindrical channel into vacuum is studied experimentally. It is shown that liquid film at the exit edge of the channel not only disintegrates into droplets, but also emerges on the external surface of the channel and starts moving in the opposite direction to the gravitational force. The phenomenon revealed is strongly dependent on physical properties of liquid and pressure in the surrounding space. Temperature of a film formed on the external surface of the channel is measured. It is shown that due to evaporation in vacuum liquid film is cooled to temperature at which the saturated vapor pressure is close to pressure in vacuum chamber.
\end{abstract}

\section{Introduction}

Recently both experimental and theoretical studies on gas jet expansion into the vacuum attracted a lot of attention. At the same time the problem of liquids expansion into the vacuum, including outflow of near-wall films combined with gas flow has not been studied thoroughly. From the practical point of view an interest in studying such flows is associated primarily with space applications. A case in point is ejection of liquids from orbital stations, including propellant refueling systems, orientation thrusters in which the fuel film is used for cooling combustion chamber and nozzle walls [1, 2]. Since the saturated vapor pressure of liquids used usually is by several orders of magnitude higher than pressure in the outer space, liquid, being ejected into the vacuum, becomes "instantly overheated". This causes liquid boiling-up, disintegration into droplets, and phase transitions on the surface and inside droplets. Co-current gas flow has a significative effect on the behavior of near-wall liquid film at the exit edge of the nozzle under ejection into the vacuum. The limiting angle of jet divergence under gas outflow from a nozzle into the vacuum exceeds $90^{\circ}$ relative to the nozzle axis. Gas flows at angles over $90^{\circ}$ are usually called backflows. It was shown [3] that under action of backflow near-wall liquid film entering vacuum at the exit edge not only disintegrates into droplets, but also emerges on the external surface of the channel and starts moving in the opposite direction even against gravitational force. Due to this effect operation of orientation thrusters of space vehicles is accompanied by backflows of propellant components droplets, which are usually harmful and should be minimized. More detailed information about the features of the near-wall liquid films expansion into vacuum and accompanying physical processes in application to modeling operation of space vehicles and orbital stations orientation thrusters, including the International Space Station (ISS), can be found in [4, 5]. It should

${ }^{\text {a }}$ Corresponding author : yarygin@itp.nsc.ru 
be noted that in these studies ethanol was used as a model liquid because its main physical properties (density, saturated vapor pressure, heat of vaporization, viscosity, surface tension) are close to unsymmetrical dimethylhydrazine, which is currently used as a fuel for ISS orientation thrusters. We can conclude that the observed phenomenon of near-wall film emergence on the external surface, its rise and further evolution, including phase transitions (evaporation, cooling down up to freezing) depend mainly on the physical properties of the liquid (saturated vapor pressure and heat of vaporization) and therefore represent independent scientific interest. The current paper is devoted to experimental study on the effect of physical properties of monoliquids and binary mixtures on the process of near-wall film expansion with co-current gas flow from cylindrical channel into the vacuum.

\section{Experimental setup and measurement techniques}

Experiments were carried out on a VIKING vacuum gas-dynamic setup of Kutateladze Institute of Thermophysics. The large volume of the working chamber $\left(150 \mathrm{~m}^{3}\right)$ allowed operation in pulse mode with high flow rates of gas and liquid. Cylindrical channel with $5 \mathrm{~mm}$ diameter, $20 \mathrm{~mm}$ length and 1 $\mathrm{mm}$ wall thickness was mounted vertically in the vacuum chamber, with exit part facing downwards. The liquid entered through a circular gap of $0.1 \mathrm{~mm}$ width into the stagnation chamber of the channel (nozzle) and moved down the nozzle walls as a film. Simultaneously, gas was blown through the nozzle. At the nozzle exit, a freely expanding gas jet with dispersed liquid droplets was formed. Time interval of gas and liquid feeding was equal several seconds, and it was sufficient for quasi-steady flow conditions settlement. Initially both gas and liquid were at room temperature, initial pressure in vacuum chamber for majority of experiments was equal to $1 \mathrm{~Pa}$, and the final one could be $1-2$ orders of magnitude higher. Snapshots of the liquid film outflow process into the vacuum were taken in experiments with the help of a digital camera, and liquid film temperature at the external surface of the channel was measured by Texas Instruments LM50 temperature sensors.

We used purified air as a working gas, and ethanol, dodecane, water and water-ethanol mixture as working liquids. Their physical properties are shown in Table 1. Dodecane was chosen as a liquid with many similar physical properties but with much lower saturated vapor pressure as compared to ethanol. Water, which has high heat of evaporation, was chosen as a working liquid because of a number of important applications in the field of aerospace technologies. Although a number of papers studied water injection into vacuum from tubes accompanied by droplet formation and freezing [6-7] we found no studies on ejection of water in the form of near wall film. As liquid film behaviors of pure ethanol and pure water are drastically different under ejection into vacuum, we also used water-ethanol mixture to achieve better understanding of the ejection process.

Table 1. Physical properties of working liquids.

\begin{tabular}{|c|c|c|c|c|c|}
\hline Parameter & Units & $\begin{array}{c}\text { Ethanol } \\
\mathbf{C}_{2} \mathbf{H}_{6} \mathbf{O}\end{array}$ & $\begin{array}{c}\text { Dodecane } \\
\mathbf{C}_{\mathbf{1 2}} \mathbf{H}_{\mathbf{2 6}}\end{array}$ & $\begin{array}{c}\text { Water } \\
\mathbf{H}_{2} \mathbf{O}\end{array}$ & $\begin{array}{c}\text { Water-eth. } \\
\mathbf{5 0 \%} \text { (vol.) }\end{array}$ \\
\hline Saturated vapor pressure at $20^{\circ} \mathrm{C}$ & $\mathrm{kPa}$ & 5.86 & 0.0097 & 2.31 & 3.3 \\
\hline Dynamic viscosity at $20^{\circ} \mathrm{C}$ & $\mathrm{Pa} \cdot \mathrm{s}, 10^{-3}$ & 1.2 & 1.492 & 1.002 & 2.77 \\
\hline Density at $20^{\circ} \mathrm{C}$ & $\mathrm{kg} / \mathrm{m}^{3}, 10^{3}$ & 0.79 & 0.75 & 1 & 0.927 \\
\hline Surface tension at $20^{\circ} \mathrm{C}$ & $\mathrm{N} / \mathrm{m}, 10^{-3}$ & 22.8 & 25.5 & 72.8 & 27 \\
\hline Melting point at $100 \mathrm{kPa}$ & ${ }^{\circ} \mathrm{C}$ & -114.5 & -9.55 & 0 & -32.5 \\
\hline Boiling point at $100 \mathrm{kPa}$ & ${ }^{\circ} \mathrm{C}$ & 78.3 & 216.3 & 100 & 83 \\
\hline Heat of vaporization at $100 \mathrm{kPa}$ & $\mathrm{kJ} / \mathrm{kg}$ & 840 & 360 & 2256 & 1859 \\
\hline
\end{tabular}

\section{Results}

Snapshots of near-wall film ejection process into the vacuum chamber with chamber pressure of $1 \mathrm{~Pa}$ for dodecane, ethanol and water are shown in Fig. 1. Flow patterns during ejection into the vacuum for 
all working liquids show emergence of near-wall liquid film on the external surface of the channel and backward motion even against gravity. This is drastically different from the ejection into the atmosphere when usual gas-droplet flow takes place behind the nozzle edge.
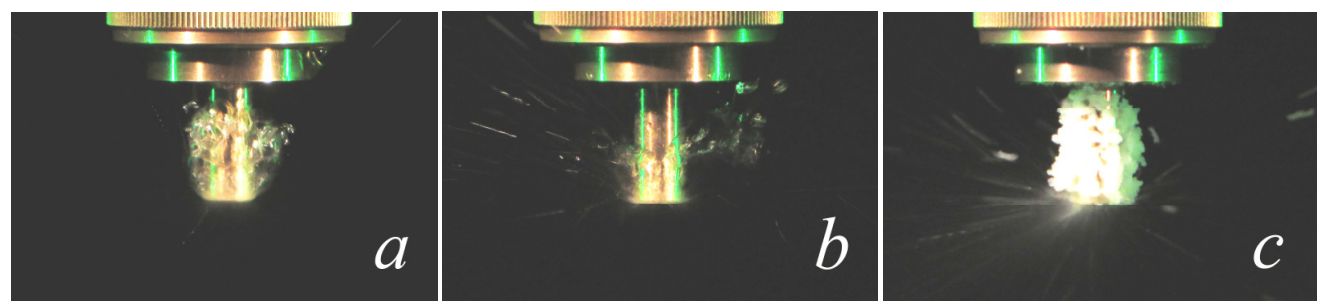

Figure 1. Outflow of liquid films into the vacuum. $a$ - dodecane, $b$ - ethanol, $c$ - water.

Snapshots in Fig. 1 show the flow at the moment of maximum film rise. One can see, that rise of dodecane film is the highest, probably because dodecane has the smallest saturated vapor pressure. For the same reason dodecane film entering the vacuum chamber doesn't go through explosive disintegration into droplets as shown in Fig. 1a. Rise of ethanol film is the smallest and ethanol film entering the vacuum chamber shows significant disintegration of liquid film into droplets under its motion over the external surface of the nozzle. Arguably this behavior is due to high saturated vapor pressure of ethanol at room temperature that leads to instant overheating of ethanol film. The process of intensive droplet detachment from external surface in experiments with ethanol is shown in Fig. $1 b$. A special feature of water near-wall film ejection into the vacuum is formation of ice layer on the external surface of the nozzle. Although this phenomenon was expected in experiment, the rise of the ice layer to the full height of the tube shown in Fig. $1 c$ was unanticipated. As for liquid film of waterethanol mixture, its behavior during the experiment was close to the one of ethanol film. However upon discontinuation of liquid feeding remaining liquid film on the external surface started to freeze. Presumably it is caused by faster evaporation of ethanol into the vacuum and increase in concentration of water component in mixture.

Liquid film temperature measurement results for water, ethanol, and water-ethanol mixture with $50 \%$ volumetric concentration under ejection into the vacuum chamber with initial pressure of $1 \mathrm{~Pa}$ are shown in Figure 2.

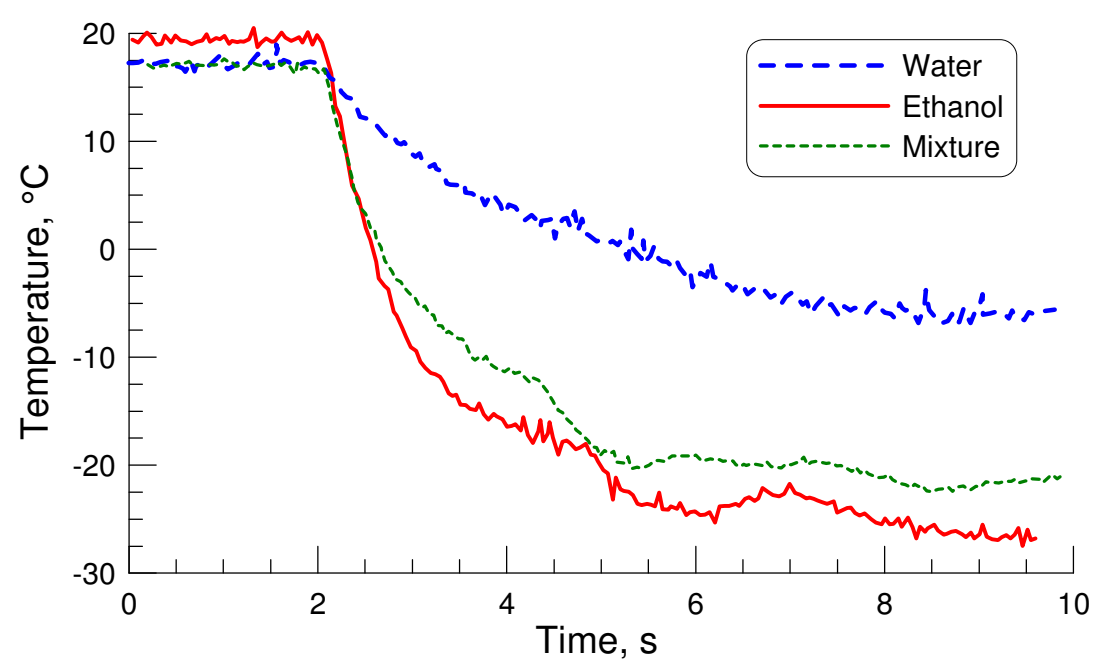

Figure 2. Liquid film temperature on the external surface of the nozzle near its exit edge.

Gas feeding was started in experiments at the moment of time $t=0.9 \mathrm{~s}$ and stopped at $t=4.9 \mathrm{~s}$, while liquid feeding was started at $t=1.0 \mathrm{~s}$ and stopped at $t=4.2 \mathrm{~s}$. One can see that it takes about $1 \mathrm{~s}$ 
for liquid film to reach the nozzle exit edge. At the exit edge liquid film emerges on external surface and begins to cool intensively. Temperature results allowed us to better understand how liquid films are cooled under considered conditions at different absolute pressures in vacuum chamber (from 1 to $1300 \mathrm{~Pa}$ ). It was shown that the final temperature of liquid film depends on the vacuum chamber pressure $p_{\mathrm{c}}$. For example for ethanol, which does not freeze in the vacuum, at $p_{\mathrm{c}}=1300 \mathrm{~Pa}$ liquid film is cooled to the temperature of about $-4{ }^{\circ} \mathrm{C}$, and at $p_{\mathrm{c}}=130 \mathrm{~Pa}$ the film temperature decreases to $-28^{\circ} \mathrm{C}$. This result has a clear explanation, assuming that the film of ethanol is cooled to the temperature, at which the pressure of saturated ethanol vapors becomes close to the pressure in the vacuum chamber. In other words, the lower the pressure in the vacuum chamber, the lower the temperature of the liquid film. For water the situation is different due to the fact that water undergoes phase transition in our experiment. According to the measurement results, at $p_{\mathrm{c}}=1300 \mathrm{~Pa}$ the water film is cooled to $T \approx 1.5^{\circ} \mathrm{C}$, and at $p_{\mathrm{k}}=130 \mathrm{~Pa}$ it freezes and the temperature drops to $T \approx-5.5^{\circ} \mathrm{C}$. From Fig. 2 it is possible to see, that temperature of water-ethanol mixture is higher than for pure ethanol and lower than for pure water, but further detailed study on effect of composition ratio on film temperature is required. As for dodecane, it was shown that due to low saturated vapor pressure it is almost not subject to evaporation, therefore its film temperature is nearly steady in experiments.

\section{Conclusion}

A series of experimental studies on jet expansion of gas from a cylindrical channel with near-wall liquid film into the vacuum was carried out. It was shown that under expansion into the vacuum physical properties of liquids (primarily saturated vapor pressure and heat of vaporization) and pressure in the surrounding space (vacuum chamber) determine film behavior at the exit edge of the channel (backward turn, emergence on the external surface, and rise even against gravity) and its further evolution (disintegration into droplets, cooling down to freezing). Our results expand existing knowledge on the features of liquids ejection into the vacuum in the form of thin films, and could be relevant for a number of space applications.

\section{Acknowledgments}

The study was supported by the Russian Foundation for Basic Research, research project No. 16-0800436.

\section{References}

1. H. Trinks, AIAA Paper No. 87-1607 (1987).

2. H. Trinks, I. Kaelsch, AIAA Paper No. 87-1603 (1987).

3. V.N. Yarygin, V.G. Prikhodko, I.V. Yarygin, Yu.N. Vyazov, Vacuum, 109, 401-404 (2014).

4. V.N. Yarygin, Yu.I. Gerasimov, A.N. Krylov, L.V. Mishina, V.G. Prikhodko, and I.V. Yarygin, Thermophys. Aeromech., 18, 333-358 (2011).

5. V. Yarygin, Yu. Gerasimov, A. Krylov, V. Prikhodko, and I. Yarygin, Microgravity Sci. Technol., 23, 15-23 (2011).

6. H. Fuchs, H. Legge, Acta Astronaut., 6, 1213-1226 (1979).

7. J.W. Alred, N.L. Smith, K.C. Wang, F.E. Lumpkin, and S.M. Fitzgerald, TFAWS (1997). 